\title{
Mechanism of Bacterial Bioluminescence: 4a,5-Dihydroflavin Analogs as Models for Luciferase Hydroperoxide Intermediates and the Effect of Substituents at the 8-Position of Flavin on Luciferase Kinetics ${ }^{\dagger}$
}

\author{
Jens W. Eckstein, ${ }^{\ddagger}$ J. Woodland Hastings, ${ }^{*}$ and Sandro Ghisla* \\ Department of Biology, University of Konstanz, POB 5560, 7750 Konstanz, Germany, and Department of Cellular and \\ Developmental Biology, Harvard University, 16 Divinity Avenue, Cambridge, Massachusetts 02138
}

\begin{abstract}
Bioluminescence catalyzed by bacterial luciferases was measured using FMN, iso-FMN (6methyl-8-nor-FMN), and FMN analogs carrying the following substituents at position 8: $-\mathrm{H},-\mathrm{Cl},-\mathrm{F}$, $-\mathrm{SMe},-\mathrm{SOMe},-\mathrm{SO}_{2} \mathrm{Me}$, or $-\mathrm{OMe}$. The first-order rate constants for the decay of light emission correlate with the one-electron oxidation potentials of the 4a,5-dihydro forms of the FMN analogs. To determine the values of these potentials, isoalloxazine (flavin) derivatives having the 4a,5-propano-4a,5-dihydro structure and $-\mathrm{H},-\mathrm{CH}_{3},-\mathrm{Cl},-\mathrm{OCH}_{3}$, and $-\mathrm{NH}_{2}$ as substituents at position 8 have been synthesized as models for the 4a-peroxy-4a,5-dihydroflavin intermediates occurring during catalysis by the flavin-dependent monooxygenase luciferase. The tetrahydropyrrole ring between positions $4 \mathrm{a}$ and 5 of these isoalloxazine derivatives stabilizes the 4a,5-dihydroflavin by impeding formation of the thermodynamically more stable 1,5-dihydro form. One-electron oxidation potentials $\left(E_{\text {obs }}\right)$ were measured by cyclic voltammetry and used to determine the empirical coefficients in the Swain equation. On the basis of this, the one-electron oxidation potentials of 4a,5-propano-4a,5-dihydro analogs with other substituents in position 8 were calculated $\left(E_{\text {calc }}\right)$. The bioluminescence reaction rate is fastest with FMN analogs of lowest oxidation potential; i.e., the slope of the correlation is negative. This indicates that in the rate-limiting step the 4a,5-dihydroflavin moiety donates negative charge. The results are compatible with an intramolecular, chemically initiated electron exchange luminescence mechanism for the bacterial luciferase reaction. A good correlation was also found between $E_{\text {obs }}$ and the literature values of the 2-electron oxidation/reduction potentials $\left(E_{\text {redox }}\right)$ of the couple $\mathrm{FI}_{\mathrm{ox}} / 1$,5-dihydro-FI $\mathrm{F}_{\text {red }}$ for the flavin derivatives having the same substituent at position 8 . The effects of the substituent in position 8 on the redox properties of 1,5-dihydro- and 4a,5-dihydroflavins are thus essentially the same. This indicates that the earlier use of readily available redox potentials for $\mathrm{FI}_{\mathrm{ox}} / 1,5$-dihydro- $\mathrm{FI}_{\text {red }}$ for studying reactions involving the 4a,5-dihydro isomer was sound.
\end{abstract}

Bacterial luciferase (E.C. 1.14.14.3) catalyzes the monooxygenation of long-chain aldehyde to the corresponding carboxylic acid concomitant with production of light; the cosubstrate is $\mathrm{FMNH}_{2}{ }^{1}$ which is oxidized to $\mathrm{FMN}$ in the course of the following reaction (Hastings et al., 1985):

$$
\begin{gathered}
\mathrm{FMNH}_{2}+\mathrm{RCHO}+\mathrm{O}_{2} \stackrel{\text { luciferase }}{\rightarrow} \mathrm{FMN}+\mathrm{RCOOH}+ \\
\mathrm{H}_{2} \mathrm{O}+h \nu(490 \mathrm{~nm})
\end{gathered}
$$

This enzyme formally belongs to the class of flavindependent monooxygenases, in which the oxygenating species is the 4a,5-dihydroflavin-4a-hydroperoxide. However, it is becoming increasingly clear that there are basic mechanistic differences between bacterial luciferase (Ahrens et al., 1991)

\footnotetext{
${ }^{\dagger}$ This work was supported by grants from the Deutsche Forschungsgemeinschaft to S.G. (DFG Gh. 2/4-7) and from the U.S. National Science Foundation to J.W.H. (DMB 86-16522). Scholarship support was provided from Baden-Württemberg to J.W.E. (LGFG). Presented in part at the 10th International Symposium on Flavins and Flavoproteins, Como, Italy, 1990.

I Present address: Dept. of Biochemistry, University of California School of Medicine, San Francisco, CA 94143-0448.

'Abbreviations: CIEEL, chemically initiated electron exchange luminescence; FMN, FMNH 2 , riboflavin 5'-phosphate and its reduced form.
}

and the "classical (flavin-dependent) hydroxylases" (Bruice 1982a, 1984; Keum et al., 1990), especially the production of excited states.

Luciferases purified from different bacterial species are similar in structure ( $\alpha \beta$ heterodimers), molecular mass ( $\sim 79$ $\mathrm{kDa}$ ), and amino acid sequence (Ruby \& Hastings, 1980; Hastings et al., 1985). Although there are substantial differences with respect to the rates of catalysis, it is likely that the same basic mechanism is operative in all cases. Some years ago, the CIEEL mechanism (chemically initiated electron exchange luminescence) was put forward for the chemiluminescence reaction of some peroxides and dioxetanones (Koo \& Schuster, 1977; Schuster, 1979). Such a mechanism was also formulated for the bacterial bioluminescence reaction, as depicted in Scheme I (Macheroux et al., 1984; Mager \& Addink, 1984; Mager et al., 1988).

The CIEEL mechanism predicts that the oxidation potential of the flavin should affect the rate of the bioluminescence reaction. Indeed, this was found to be so in experiments with substituted FMN analogs (Eckstein et al., 1988; Macheroux et al., 1984, 1987). The modified flavins used in those studies carried various substituents, including several at position 8 , and a free energy relationship analysis was applied. In that analysis, the redox potentials of the $\mathrm{FI}_{0 \mathrm{x}} / 1,5-\mathrm{FI}_{\text {red }} \mathrm{H}_{2}$ couples 
Scheme I: Steps and Intermediates for a Chemically Initiated Electron Exchange Luminescence (CIEEL) Mechanism Adapted from Schuster (1979) to the Intramolecular Case of the Bacterial Luciferase Reaction ${ }^{a}$<smiles></smiles><smiles></smiles><smiles>[3H][Hg]CC[12CH3]</smiles>

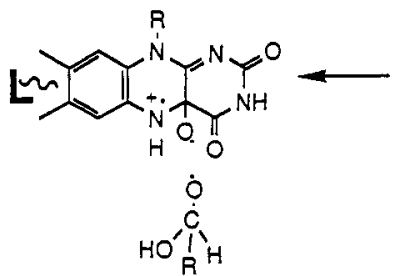

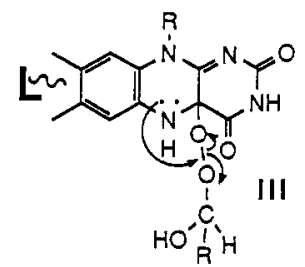

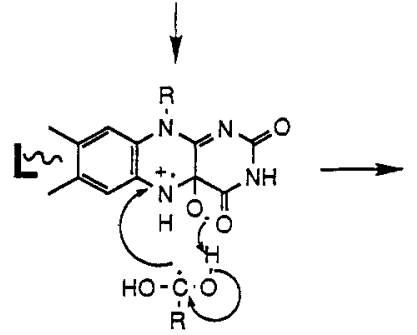

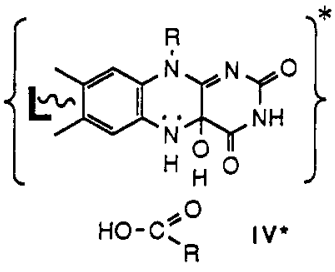

${ }^{a} \mathrm{I}$ is the reduced FMN-luciferase complex, II is the enzyme-bound flavin-4a-hydroperoxide, III is its peroxyhemiacetal with long-chain aldehyde, and $I \mathrm{IV}^{*}$ is the postulated excited state which decays to the flavin-4a-hydroxyde concomitant with emission of light. Subsequently, dehydration leads to reformation of oxidized FMN (not shown) ( $\mathrm{L}=$ luciferase, $\mathrm{R}=$ ribityl-5'-monophosphate).

were used, since those of the $\mathrm{FI}_{\text {ox }} / 4 \mathrm{a}, 5-\mathrm{FI}_{\mathrm{red}} \mathrm{H}_{2}$ couples or those of the $\mathrm{FIH} \cdot / 4 \mathrm{a}, 5-\mathrm{FI}_{\mathrm{red}} \mathrm{H}_{2}$ couples were not available, due to the instability of the fully reduced species $(4 a, 5-$ dihydroflavins have never been observed in the absence of appropriate substituents at $\mathrm{C}(4 \mathrm{a})$ or $\mathrm{N}(5)$ ). The assumption was thus made that the substituents would affect these two pairs of couples similarly.

The validity of this assumption is supported by the present work (part I), in which we have synthesized various stable 4a,5-dihydroflavin model compounds (Figure 1), all substituted in the 8-position. We have measured their one-electron oxidation potentials by cyclic voltammetry and found that these correlate linearly with the corresponding redox potentials.

In part II, we have extended the experiments previously done with Vibrio harveyi (Macheroux et al., 1987) to include additional analogs and also luciferase from Vibrio fischeri. For comparison, we include data from the literature for Photobacterium phosphoreum (Watanabe et al., 1978).

The single-turnover kinetic parameters of the light-emitting reaction were determined using various 8-substituted FMN analogs and analyzed on the basis of a linear free energy relationship. This single-turnover assay, initiated by the addition of the reduced form of the flavin, is especially suited for kinetic analysis. All molecules not initially bound to luciferase will spontaneously reoxidize within $\sim 1 \mathrm{~s}$ and therefore are not involved in the enzymatic reaction. The luciferase bound reduced flavin (I, Scheme I) will react with molecular oxygen and form the flavin-4a-hydroperoxide (intermediate II; Hastings \& Gibson, 1963; Hastings et al., 1973). Binding of long-chain aldehydes to II is very fast and not rate determining (Baumstark et al., 1979). This obser- vation implies that the rate of decay of the light emission intensity reflects the decay of the luciferase-bound $4 a-$ peroxyhemiacetal-4a,5-dihydroflavin intermediate (III), a first-order process. Thus, logarithmic plots of light emission intensity versus time yield rate constants for the decay of III (Hastings \& Gibson, 1963).

\section{MATERIALS AND METHODS}

General Instrumentation. UV/vis spectra were measured with a Kontron UVIKON 930 spectrophotometer. 'H-NMR spectra were recorded with a JEOL GX $400(400-\mathrm{MHz})$ spectrometer at $25^{\circ} \mathrm{C}$ in $\mathrm{CDCl}_{3}(2,3,4,5$; for numbering see Figure 1) or DMSO- $d_{6} / \mathrm{CF}_{3} \mathrm{COOH}(1)$. A $25 \mathrm{~cm} \times 2.0 \mathrm{~cm}$ RP-18 LiChrosorb HPLC column was used for purification of compounds 1, 2, and 5 using $70 \%$ methanol $/ 30 \% 20 \mathrm{mM}$ phosphate buffer, $\mathrm{pH} 6.0(\mathrm{v} / \mathrm{v})$.

Chemicals. DEAE-Sephacel, G25 gel filtration material, and $\mathrm{CNBr}$-activated Sepharose-4B were purchased from Pharmacia; HA-Ultrogel was from LKB. $\mathrm{FMNH}_{2}$ was prepared by reduction of $\mathrm{FMN}$ by $\mathrm{H}_{2} / \mathrm{Pt}$ asbestos.

Syntheses. (UV/vis spectra are in Figure 2; NMR data are in Table I.) The 8-substituted 3,7,10-trimethylisoalloxazines, 3-methyl-lumiflavin, 3,7,10-trimethylisoalloxazine, and 3,7-dimethyl-8-methoxy-10-ethylisoalloxazine were synthesized according to described procedures (Berezovskii et al., 1972; Ghisla et al., 1973; Hemmerich et al., 1959, 1960; Kasai et al., 1987).

3-Methyl-4a,5-propano-4a,5-dihydroisoalloxazine (3) was synthesized according to Ghisla et al. (1974) with a yield of $30 \%$, the course of the reaction being followed also by TLC or HPLC (reversed-phase, methanol/ $\mathrm{H}_{2} \mathrm{O}$ gradient).

3,7,10-Trimethyl-4a,5-propano-4a,5-dihydroisoalloxazine (4) was synthesized following the procedure of Ghisla et al. (1974), with the difference that the reaction mixture was stirred for $\sim 15 \mathrm{~h}$ at room temperature. The pure compound was obtained by recrystallization from ethanol/ water. Yield was $25 \%$.

3,7,10-Trimethyl-8-chloro-4a,5-propano-4a,5-dihydroisoalloxazine (5) is comparatively very unstable and sensitive to oxygen. For its alkylation, $100 \mathrm{mg}$ of 8-chloro-3,7,10trimethylisoalloxazine was suspended in nitrogen-flushed 10 $\mathrm{mL}$ of $\mathrm{H}_{2} \mathrm{O} / \mathrm{DMF}(1: 1 \mathrm{v} / \mathrm{v})$ buffered with $400 \mathrm{mg}$ of $\mathrm{K}_{2} \mathrm{CO}_{2}$ and reduced by addition of $300 \mathrm{mg}$ of $\mathrm{Na}_{2} \mathrm{~S}_{2} \mathrm{O}_{4}$ under nitrogen. After dissolution of the flavin, 5 equivalents of 1,3-dibromopropane were added and the reaction mixture was stirred at $60^{\circ} \mathrm{C}$ for 2 days. Small amounts of $\mathrm{Na}_{2} \mathrm{~S}_{2} \mathrm{O}_{4}$ were required from time to time to ensure anaerobic conditions. After completion of the reaction (disappearance of the $442-\mathrm{nm}$ absorption of the oxidized flavin in an acidified and aerated sample), the neutralized ( $2 \mathrm{~N}$ acetic acid) reaction mixture was evaporated to dryness and applied to a Silica column (30 $\times 2.5 \mathrm{~cm}$ ) under nitrogen. The crude product was eluted with $\mathrm{CH}_{2} \mathrm{Cl}_{2} / \mathrm{MeOH}(95: 5 \mathrm{v} / \mathrm{v}$.). The second band eluting had a bright, yellow-green color and was evaporated to dryness immediately. Final purification was achieved by HPLC.

3,7,10-Trimethyl-8-methoxy-4a,5-propano-4a,5-dihydroisoalloxazine (2) and 3,7,10-Trimethyl-8-amino-4a,5propano-4a,5-dihydroisoalloxazine (1). Synthesis was carried out according to the procedure of Ghisla et al. (1974), with the difference that the reaction mixtures were stirred for 60 (2) and 20 (1) min at room temperature. Purification was achieved as for compound 3. The yields for both compounds were $\sim 35 \%$.

Cyclic Voltammetry. These experiments were done using an electrochemical cell developed by Kiesele (1980) under an 
argon atmosphere, which assures the absence of traces of water. Commercial acetonitrile (Merck) was purified (Kiesele, 1981). Measurements were carried out in acetonitrile containing 0.1 $\mathrm{M}$ tetrabutylammonium perchlorate at $25^{\circ} \mathrm{C}$. The concentrations were $\sim 6 \mathrm{mM}$ for 1,3 , and $4, \sim 2.5 \mathrm{mM}$ for 2 , and $\sim 0.5 \mathrm{mM}$ for 5 . Single-sweep voltammograms were recorded with a PAR 170 electrochemistry system using a special electrolysis cell. The combined working and counter electrode consisted of a 1-mm-diameter polished platinum disk and a $0.5-\mathrm{mm}$ platinum wire spiral, both sealed in a soft glass tube. All measurements were carried out at $25^{\circ} \mathrm{C}$ under stirring, and against a $\mathrm{Ag} / \mathrm{Ag}^{+}$reference electrode ( $0.01 \mathrm{M} \mathrm{AgNO}_{3}$ in $\left.0.1 \mathrm{M} \mathrm{NBu}_{4} \mathrm{ClO}_{4} / \mathrm{MeCN}\right)$. The electrolytic solution $(0.2$ $\mathrm{MNBu}_{4} \mathrm{ClO}_{4} / \mathrm{MeCN}$ ) was passed twice over the drying tube under an atmosphere of dry argon at $-20^{\circ} \mathrm{C}$ to remove trace amounts of water. Scan rates tested were $0.1,1.0$, and 10.0 $\mathrm{V} / \mathrm{s}$. The best results were obtained with a rate of $0.1 \mathrm{~V} / \mathrm{s}$. Ferrocene was used for calibration (standard one-electron oxidation potential $E^{\circ}=307 \mathrm{mV}$ ).

Voltammograms of the model compounds are depicted in Figure 3. Peak separations were estimated graphically, the error is $\pm 5 \%$. Since some of these systems may not be fully reversible, the potentials of the peaks of oxidation and reduction were averaged and called $E_{\text {obs }}$ (to distinguish them from standard one-electron potentials not experimentally accessible here).

The $2 \mathrm{e}^{-}$redox potentials $\left(E_{\text {redox }}\right.$, for the couple $\mathrm{FI}_{\mathrm{ox}} / 1,5-$ dihydro- $-\mathrm{FI}_{\text {red }} \mathrm{H}_{2}$ ) of the isoalloxazines (flavins) substituted in position 8 with the groups listed in Table III were taken from the literature: for $1,-330 \mathrm{mV}$ (Kasai et al., 1978), $-310 \mathrm{mV}$ (Stewart \& Massey, 1985); for 2, $-260 \mathrm{mV}$ (Kasai et al., 1979), -284 (pH 7.26) (Ghisla \& Mayhew, 1980); for 3,-208 $\mathrm{mV}$ (Draper \& Ingraham, 1968); for 4,-180 mV (McCormick et al., 1963); for 5, $152 \mathrm{mV}$ (Light \& Walsh, 1980); for 6, $-167 \mathrm{mV}$ (this work); for 7, $-204 \mathrm{mV}$ (Moore et al., 1979); for 8, $-161 \mathrm{mV}$ (Macheroux et al., 1990; this work); for 9, -50 $\mathrm{mV}$ (Moore et al., 1979); for 10,-200 mV (Müller \& Massey, 1969); for 11, -246 mV (Kasai et al., 1979); for 12, -148 mV (Fritz et al., 1990). The two-electron redox potentials $\left(E_{\text {redox }}\right)$ of analogs 6 and $8(-161 \mathrm{mV})$ were determined according to Foust et al. (1969).

A linear free energy relationship analysis was performed using the optimized Swain substituent coefficients (Swain \& Lupton, 1968; Swain et al., 1983). According to this method, the sensitivity of a reaction to various substituents can be expressed by the polynomial

$$
P_{i}=r R_{i}+f F_{i}+c
$$

where $P_{i}$ is the predicted datum (here the value of $E_{\text {obs }}$ ), $R_{i}$ is the mesomeric coefficient of substituent $i$, and $F_{i}$ is the nonmesomeric (inductive) coefficient of this substituent. The values of $R_{i}$ and $F_{i}$ are taken from Table I of Swain et al. (1983). The values of $r, f$, and $c$ were obtained by leastsquare fitting of the polynomial using the $P_{i}\left(E_{\text {obs }}\right)$ values for compounds 1-5 (Figure 4). Values of one-electron oxidation potentials $\left(E_{\text {calc }}\right)$ could then be calculated for these and all other substituents listed in Swain's table.

These one-electron oxidation potentials of 4a,5-dihydroflavin model compounds, referred to as $E$ for simplicity, were therefore used in the comparisons of the effect of flavin substituents on the rate constant for the decay of light emission in the luciferase reactions.

Ionization potentials of model compounds 1,3 , and 5 were calculated with the MOPAC software package using the AM1

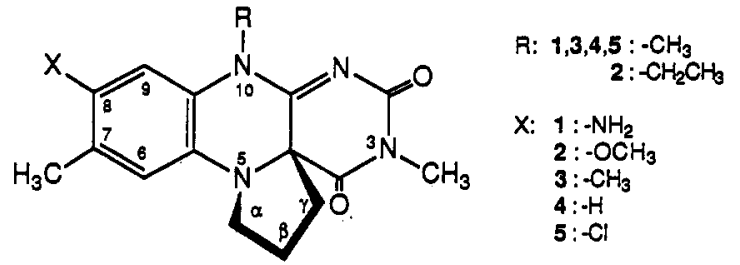

FIGURE 1: General structure and numbering of flavin model compounds used in this work. Note that the term flavin refers to 10-substituted-7,8-dimethylisoalloxazine.

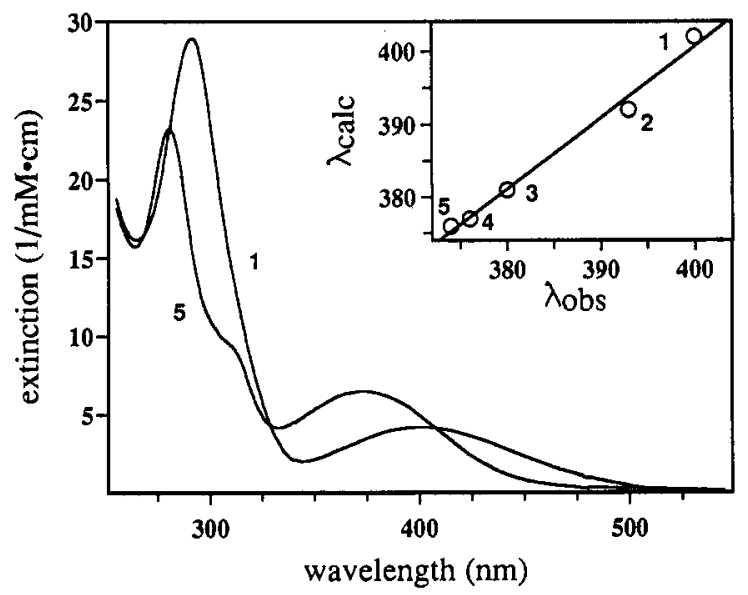

FIGURE 2: UV/vis spectra of two of the flavin model compounds (1 and 5) in methanol. Inset: Correlation of observed $\lambda_{\max }$ values for compounds 1-5 with those calculated using Swain substituent coefficients. The specific values used for the Swain polynomial were $r=-10.454, f=-4.035$, and $c=376.67$ (Swain et al., 1983). See Figure 1 for structures of compounds.

Hamiltonian on a DEC Microvax computer (Dewar et al., 1985).

Luciferases were purified by affinity chromatography (Baldwin et al., 1986). Protein concentrations were estimated by absorbance at $280 \mathrm{~nm}$ and also by the Coomassie blue method (Bradford, 1976) with BSA as the protein standard. Estimates of luciferase concentrations were based on a molecular mass of $79 \mathrm{kDa}$.

Dissociation constants $\left(K_{d}\right)$ for the binding of reduced FMN to luciferase were obtained by the method of Eadie-Hofstee using the maximal initial light emission intensities in standard assays at different $\mathrm{FMNH}_{2}$ concentrations (Meighen \& Hastings, 1971). The light intensity is directly proportional to the concentration of the luciferase- $\mathrm{FMNH}_{2}$ complex (Hastings \& Gibson, 1963). The luciferase concentration was about $1 \mu \mathrm{M}$; aldehyde was added as a saturated solution in $0.1 \% \mathrm{EtOH}$ and FMN analogs were used in the range of $50 \mu \mathrm{M}$.

Bioluminescence emission spectra of in vitro reactions were recorded either by performing the standard assay in the presence of dodecylamine, which slows down the reaction like dodecanol (Tu, 1979; Makemson et al., 1992), or by reductasecoupled assays (Hastings et al., 1978) performed on a PerkinElmer MPF-4 or a SPEX Fluorolog 1681 spectrofluorometer. All spectra, were corrected for spectral response of the equipment.

\section{RESULTS AND DISCUSSION}

\section{4a,5-Dihydroflavin Analogs as Models for Luciferase Hydroperoxide Intermediates}

Synthesis of 4a,5-Propano-4a,5-dihydroflavin Derivatives. These compounds were obtained in yields between $5 \%$ and 
Table I: 'H-NMR Data of 4a,5-Dihydro-4a,5-propano Flavin Model Compounds ${ }^{a}$

\begin{tabular}{|c|c|c|c|c|c|}
\hline & & $d$ & & & \\
\hline hydrogen & $1\left(-\mathrm{NH}_{2}\right.$ & $2(-\mathrm{OMe})$ & $3(-\mathrm{Me})$ & $4(-\mathrm{H})$ & $5(-\mathrm{Cl})$ \\
\hline $\begin{array}{l}\text { (6)-H } \\
(9)-\mathrm{H} \\
(8)-\mathrm{H}\end{array}$ & $\begin{array}{l}6.55(\mathrm{~s}) \\
6.5(\mathrm{~s})\end{array}$ & $\begin{array}{l}6.63(\mathrm{~s}) \\
6.45(\mathrm{~s})\end{array}$ & $\begin{array}{l}6.73(\mathrm{~s}) \\
6.6(\mathrm{~s})\end{array}$ & $\begin{array}{l}6.55 \\
6.9(\mathrm{~m}) \\
7.45(\mathrm{~m})\end{array}$ & $\begin{array}{l}6.93(\mathrm{~s}) \\
6.65(\mathrm{~s})\end{array}$ \\
\hline $\mathrm{N}(5)-\alpha-\mathrm{CH}_{2}^{-}$ & $\begin{array}{l}3.87(\mathrm{~m}) \\
3.5(\mathrm{~m})\end{array}$ & $\begin{array}{l}4.4(\mathrm{~m}) \\
3.6(\mathrm{~m}) \\
3.78(\mathrm{~s})\end{array}$ & $\begin{array}{l}4.14(\mathrm{~m}) \\
3.63(\mathrm{~m})\end{array}$ & $\begin{array}{l}3.8(\mathrm{~m}) \\
3.55(\mathrm{~m})\end{array}$ & $\begin{array}{l}4.57(\mathrm{~m}) \\
4.15(\mathrm{~m})\end{array}$ \\
\hline$(8)-\mathrm{OCH}_{3}$ & & $\begin{array}{l}3.78(\mathrm{~s}) \\
3.22(\mathrm{~s})\end{array}$ & & & \\
\hline $\begin{array}{l}\mathrm{N}(3)-\mathrm{CH}_{3} \\
\mathrm{~N}(10)-\mathrm{CH}_{3}\end{array}$ & $\begin{array}{l}3.4(\mathrm{~s}) \\
3.0(\mathrm{~s})\end{array}$ & $4.11\left(\mathrm{CH}_{2}, \mathrm{q}\right)$ & $\begin{array}{l}3.60(\mathrm{~s}) \\
3.22(\mathrm{~s})\end{array}$ & $\begin{array}{l}3.35(\mathrm{~s}) \\
3.25(\mathrm{~s})\end{array}$ & $\begin{array}{l}3.38(\mathrm{~s}) \\
3.22(\mathrm{~s})\end{array}$ \\
\hline $\mathrm{N}(5)-\beta-\mathrm{CH}_{2}^{-}$ & $2.22(\mathrm{~m})$ & $2.3(\mathrm{~m})$ & $2.28(\mathrm{~m})$ & $2.35(\mathrm{~m})$ & $2.41(\mathrm{~m})$ \\
\hline $\begin{array}{l}(7)-\mathrm{CH}_{3} \\
(8)-\mathrm{CH}_{3}\end{array}$ & & & $\begin{array}{l}2.18(\mathrm{~s}) \\
2.17(\mathrm{~s})\end{array}$ & $2.25(\mathrm{~s})$ & $2.3(\mathrm{~s})$ \\
\hline $\mathrm{N}(5)-\gamma-\mathrm{CH}_{2}^{-}$ & $1.72(\mathrm{~m})$ & $1.85(\mathrm{~m})$ & $1.87(\mathrm{~m})$ & $1.89(\mathrm{~m})$ & $1.90(\mathrm{~m})$ \\
\hline
\end{tabular}

" Spectra of compounds 2, 3, 4 , and 5 were recorded in $\mathrm{CDCl}_{3}-d_{1}$, that of 1 in DMSO- $d_{6} / \mathrm{CF}_{3} \mathrm{COOH}$. Note that the $\mathrm{N}(10)$ substituent of 2 is $-\mathrm{CH}_{2}-\mathrm{CH}_{3} . \mathrm{s}=$ singlet, $\mathrm{t}=$ triplet, $\mathrm{q}=$ quartet, $\mathrm{m}=$ multiplet.

Table II: Reaction Times and Temperatures for the Reaction of 8-Substituted 1,5-Dihydroflavins with 1,3-Dibromopropane To Give Maximum Yield of 4a,5-Propano Alkylation Products ${ }^{a}$

\begin{tabular}{lccccc}
\hline & $1\left(-\mathrm{NH}_{2}\right)$ & $2(-\mathrm{OMe})$ & $3(-\mathrm{Me})$ & $4(-\mathrm{H})$ & $5(-\mathrm{Cl})$ \\
\hline$T\left({ }^{\circ} \mathrm{C}\right)$ & 25 & 25 & 25 & 25 & 60 \\
$t(\mathrm{~h})$ & 0.3 & 1 & 3 & 12 & 48 \\
\hline
\end{tabular}

a Reactions were monitored by following the disappearance of the long-wavelength absorption of the oxidized flavin in aerated and acidified samples.

$35 \%$ by dialkylation of reduced 8 -substituted 3 -methyllumiflavins in buffered $\mathrm{H}_{2} \mathrm{O}$ /DMF with 1,3-dibromopropane. Structure assignment of $\mathbf{3}$ was based on the crystallography of the compound (Bolognesi et al., 1978), on elemental analysis, on UV/visible spectroscopy, and on 1H-NMR data (Ghisla et al., 1974). The structures of the other 4a,5-propanoisoalloxazines were deduced from the UV/visible and ${ }^{1} \mathrm{H}-\mathrm{NMR}$ data (Figure 2 and Table I). Compounds 3 and 4 were obtained as bright, yellow-green crystals and are stable against oxidation at room temperature. Compounds 1, 2, and 5 were obtained as solids upon HPLC purification; however, they could not be recrystallized. Compound 5 is particularly oxygen sensitive and must be stored at $-30^{\circ} \mathrm{C}$ under nitrogen. The effect of substitution at the 8-position on the reactivity of reduced 1,5dihydroflavins in the alkylation reaction is noteworthy. The increase of electron density of the flavin ring system by $+\mathrm{I} /$ $+\mathrm{M}$ substituents correlates with an increase of the reaction rates with 1,3-dibromopropane (Table II) as well as with the values of the absorption $\lambda_{\max }$, the oxidation potentials, and the rates of luciferase-mediated reactions.

UV/vis and NMR Spectral Data. The spectral properties of compounds $1,2,4$, and 5 are consistent with those of 3 (Ghisla et al., 1974, 1977). One salient feature is the strong influence of the substituent at the 8-position on the $\lambda_{\max }$ and $\epsilon$ of the UV/vis absorption spectra (Figure 2). Maxima are $400,393,381,376$, and $373 \mathrm{~nm}$ for $1,2,3,4$, and 5 , respectively, and $\epsilon$ varies from $4200 \mathrm{M}^{-1} \mathrm{~cm}^{-1}$ (1) to $6500 \mathrm{M}^{-1} \mathrm{~cm}^{-1}(5)$; the third transition at around $220 \mathrm{~nm}$ is of similar intensity in all compounds $\left(\epsilon \sim 45000 \mathrm{M}^{-1} \mathrm{~cm}^{-1}\right)$. A good correlation between the experimentally determined $\lambda_{\max }$ and those calculated according to the Swain relationship was found (see Figure 2, inset).

The propano bridge protons show two major effects on the ${ }^{1} \mathrm{H}-\mathrm{NMR}$ signals (for numbering refer to Figure 1). First, the two hydrogens of $C \alpha$ have chemical shift values (see Table I) ranging from 0.25 (4) to $0.8 \mathrm{ppm}$ (2). Such a pronounced anisotropy is not observed with the $C \beta$ and $C_{\gamma}$ hydrogens, and probably results from blocked inversion at the $\mathrm{N}(5)$ center affecting primarily the $\mathrm{C} \alpha$ substituents, while the two other centers of the propano bridge must retain sufficient mobility. Second, the effect of the 8-substituent is largest on the chemical shift of the bridge $\alpha$-hydrogens, although it is not systematic and clearcut. Interestingly, this effect is still remarkable on the $C \beta$ and on the $C_{\gamma}$ hydrogens $(\Delta \delta \sim 0.2 \mathrm{ppm}$ from 1 to 5, Table I) and suggests that it might be transmitted via the $\pi$-orbital system and not via the $\sigma$-bonds.

Redox Properties. One-electron oxidation was observed with all five compounds under the conditions used in cyclic voltammetry, as deduced from the peak separation $\Delta E_{\mathrm{p}}$ of the peak potentials which was $55,55,59,54$, and $65 \mathrm{mV}$ for 1 , $2,3,4$, and 5. Reversibility, as expressed by $I_{\mathrm{P}}{ }^{\mathrm{A}} / I_{\mathrm{P}}^{\mathrm{B}}$ (peak currents of the forward reaction and back-reaction), was 0.9 , $0.88,0.79,0.54$, and 1.0 for $1,2,3,4$, and 5 indicating that the corresponding radical cations have substantial lifetimes (Figure 3). The peakseparation and the quotient both indicate that the one-electron reaction is reversible. The low reversibility of the flavin 4 , which does not carry a substituent at position 8 , might be due to dimerization at this locus, which is prone to radical reactions (Haas \& Hemmerich, 1979). These considerations are in agreement with the findings of Mager et al. (1988) and of Kaaret and Bruice (1990), who determined potentials of similar magnitude for the one-electron oxidation of 4a-OH,5-ethyl-4a,5-dihydrolumiflavin. The application of semiempirical, optimized Swain substituent coefficients (Swain \& Lupton, 1968; Swain et al., 1983) yielded an excellent fit of calculated one-electron standard oxidation potentials with experimentally observed values (Figure 4). The correlation between the measured, one-electron oxidation potentials $\left(E_{\text {obs }}\right)$ of the 8-substituted 4a,5-dihydroflavins and the two-electron redox potentials of the corresponding FMN compounds $\left(E_{\text {redox }}\right)$ is also remarkably good (Figure 4$)$. The slope in this correlation is $\sim 4$, and it reflects the different sensitivity of the potentials on the substituent in the two systems.

The paraquinoid $\pi$-electron system set up by the flavin benzene ring with the $N(5)$ function and the 8-substituent is thus especially suited for mesomeric and inductive interactions, and FMN/FAD derivatives such as those described here might be useful also for the study of other flavoprotein monooxygenases and oxidases (Walsh \& Chen 1988; Ghisla \& Massey 1989). Molecular orbital calculations of the ground state indicate that the electron density at $\mathrm{N}(5)$ is very high. The ionization potentials calculated using the MOPAC method $(1,553 ; 3,575 ;$ and $5,590 \mathrm{mV})$ also exhibit a linear dependence of 8-substitution with the measured one-electron oxidation potential. From the crystal structures of $4 a, 5$-dihydroflavins (Bolognesi et al., 1978) and from the calculated structures, it appears that the bond between $\mathrm{C}(4 \mathrm{a})$ and the $\gamma$ substituent is practically perpendicular to the plane of the flavin ring system placing the bond between the $\alpha$ and $\beta$ atoms of the substituent close to the $N(5)$ lone pair orbital. The same orientation in the case of the 4a-peroxy-4a,5-dihydroflavin could lead to specific orbital-orbital interactions, which in turn could play an essential role in inducing the cleavage of the peroxide bond. Such interactions could consist of a partial charge transfer, or, in the extreme case, of the transfer of a full electron from the flavin nucleus via $N(5)$ into the peroxide bond, thus initiating the breakage of the peroxide itself. 
<smiles>[X]c1cc2c(cc1C)N1CCCC13C(=O)N(C)C(=NC(=O)N2P)N3[R]</smiles>
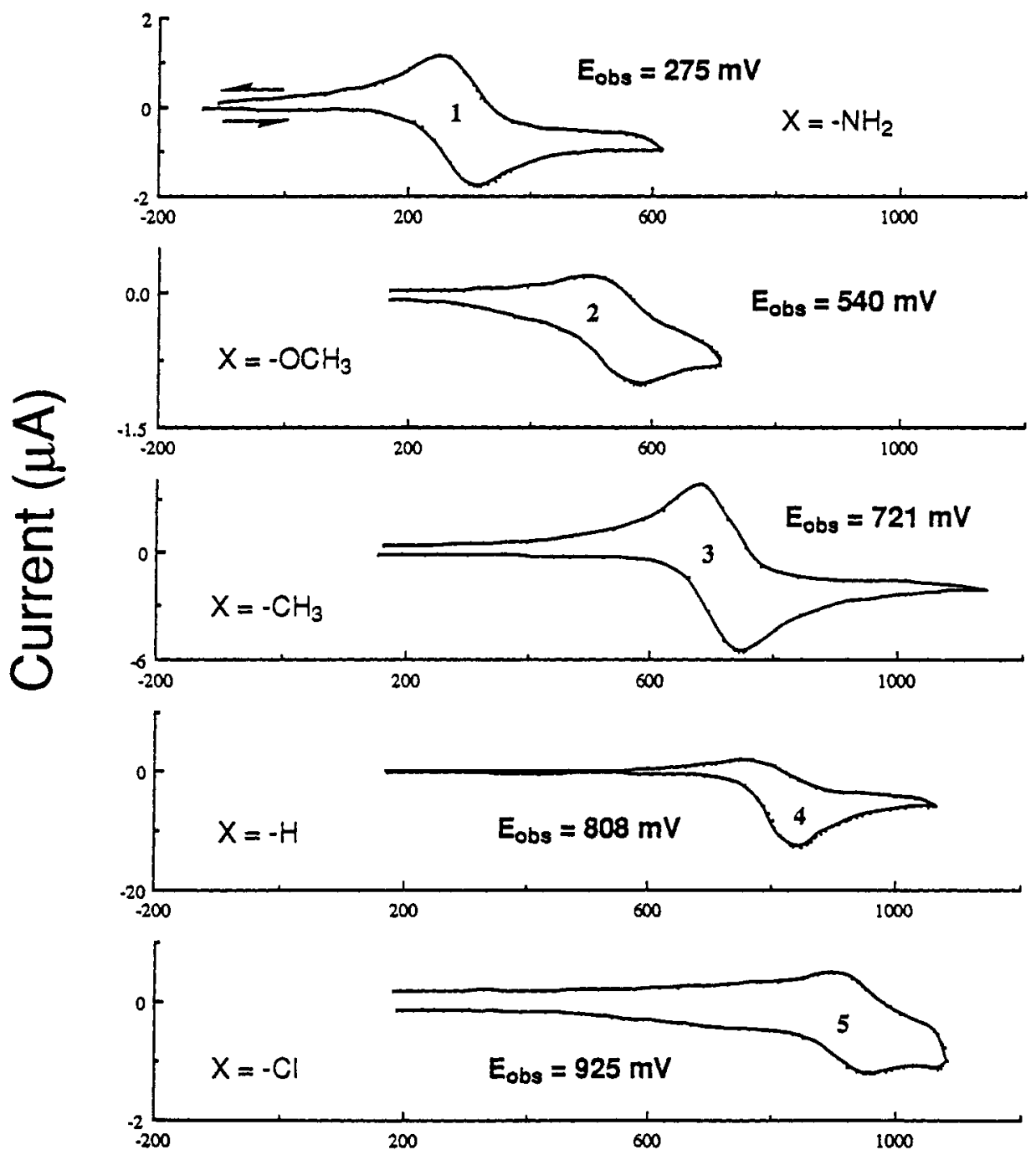

\section{Potential (mV)}

FIGURE 3: Traces from cyclic voltammetry of flavin model compounds. The lower branch is the one-electron oxidation $(\rightarrow)$, the upper branch the one electron reduction of the corresponding radical cation $(\leftarrow)$. For experimental conditions, see the text. The average of the peak potentials for oxidation and reduction is defined here as $E_{\text {obs. }}$.

\section{Linear Free Energy Relationship Analysis of the Course of Light Emission with Luciferases}

The data obtained provide a reliable basis for an interpretation of the dependence of the kinetics of the luciferase light reaction on the nature of the substituent in the 8-position. A number of reduced 8-substituted FMN analogs have been found to serve as cosubstrates with the three luciferases examined (Watanabe et al., 1978; Chen \& Baldwin 1984; Macheroux et al., 1984; 1987; Eckstein et al., 1988). As with other flavin analogs (Mitchell \& Hastings, 1969), the kinetics and emission spectrum of the in vitro bioluminescence are dependent on the analog used. Table III presents the rate constants of light emission decay $\left(k_{\text {obs }}\right)$, the maximum initial light intensities $\left(I_{\max }\right)$ relative to $\mathrm{FMNH}_{2}$, the dissociation constants of reduced cofactors/luciferase complexes $\left(K_{d}\right)$, as well as the wavelengths of the observed emission maxima $\left(\lambda_{\max }\right)$.

According to the CIEEL mechanism, or indeed any mechanism in which the rate-determining step is an electron or charge transfer, the logarithm of the rate constants of light emission decay should be dependent upon the oxidation potential of the "activator". In the postulated intramolecular activation of the peroxide by the 4a,5-dihydroflavin moiety, the relevant potentials would be the one-electron oxidation potentials of the luciferase-bound 4a,5-dihydroisoalloxazine 


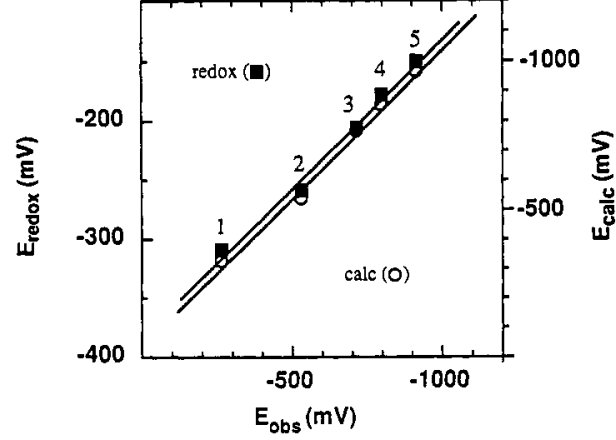

FIGURE 4: Relationships between the one-electron oxidation potentials of 4a,5-dihydroflavin model compounds measured by cyclic voltammetry ( $E_{\text {obs }}$, abscissa) with redox potentials of FMN $/ \mathrm{FMNH}_{2}$ couples having the same 8-substituents ( $E_{\text {redox }}$, ordinate, left) and also with $E$ values calculated using the method of Swain ( $E_{\text {calc }}$, ordinate, right). The reaction-specific parameters used for the Swain polynomial were $r=251.4, f=240.6$, and $c=808$. The lines were generated by least-squares fits of the data.

moiety. Since these cannot be obtained, we have used for the correlations the calculated one-electron oxidation potentials of the model compounds, referred to here simply as $E$.

Plots of $\log k_{\text {obs }}$ versus $E$ for $V$. harveyi luciferase with decanal are depicted in Figure 5. In those experiments the decay of light emission was distinctly biphasic with several of the FMN derivatives. (This behavior has been previously noted by us and other workers and appears to depend on several factors, such as aldehyde chain length, buffer or ionic concentration, and type of assay employed.) In view of this, we have plotted the rate constants for both the fast and slow phases as related to $E$. The similarity of the slopes for the two data sets indicates that the substituent at position 8 affects the two phases in a similar way. It is therefore assumed that the light emission proceeds by the same basic mechanism during the whole time course of the reaction.

A similar plot for $V$. fischeri luciferase with decanal and tetradecanal is given in Figure 6 . With both aldehydes, $k_{\text {obs }}$ again decreases when $E$ increases, but only at potentials above about $800 \mathrm{mv}$. It could be that the $V$. fischeri luciferase is more sensitive to the bulk of the substituent, which would explain the low value of $k_{\text {obs }}$ in the case of the $\mathrm{MeO}$ derivative. This possible explanation is supported by the fact that with

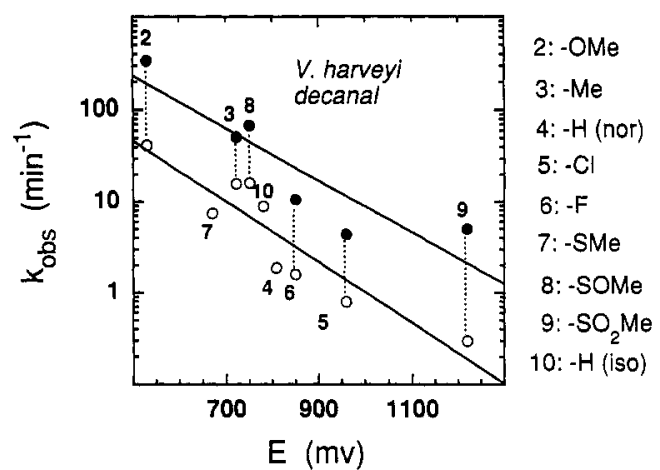

FIGURE 5: Correlation of the rates of light emission decay $\left(k_{\text {obs }}\right)$ with the calculated one-electron oxidation potentials of the 4a,5-dihydro form of the FMN analogs shown, with $V$. harveyi luciferase and decanal as substrate at $25^{\circ} \mathrm{C}$. The solid symbols represent the faster rate in the case of a biphasic decay of light emission intensity, and the open symbols represent either the slower one or the rate of the monophasic decay. The lines were generated by least-squares fits of the data. The luciferase concentrations were $\sim 1 \mu \mathrm{M}$ in all assays, and aldehyde was a saturated solution.

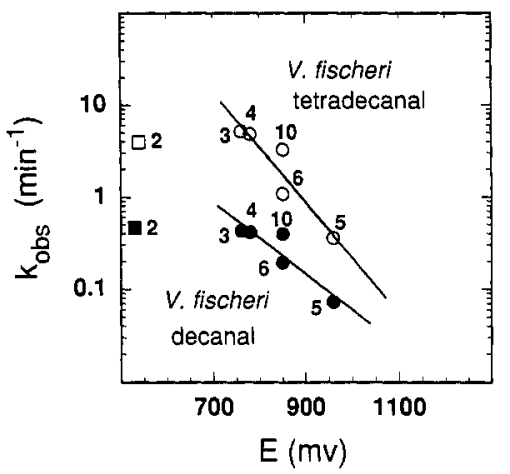

FIGURE 6: Plots as in Figure 5 with $V$. fischeri luciferase $(\sim 1 \mu \mathrm{M})$, both with decanal (solid symbols) and tetradecanal (open symbols), at $4^{\circ} \mathrm{C}$. The lines were generated by least-squares fits of the data. The rates for 8-OMe-FMN (square symbols) were not included in the fit.

this enzyme we were unable to obtain activity sufficient for data analysis with flavins substituted by other bulky groups $(7,8,9)$, indicating that in these cases the interaction with the protein might be disturbed. In general it can be noted that the fit is better for $V$. harveyi luciferase, which is known

Table III

\begin{tabular}{|c|c|c|c|c|c|c|c|c|c|c|c|c|c|c|c|c|}
\hline & \multirow[b]{2}{*}{$\begin{array}{c}\text { residue at } \\
\text { pos } 8\end{array}$} & \multirow[b]{2}{*}{$\begin{array}{l}E_{\text {redox }}^{d} \\
(\mathrm{mV})\end{array}$} & \multirow[b]{2}{*}{$\begin{array}{c}E^{e} \\
(\mathrm{mV})\end{array}$} & \multicolumn{4}{|c|}{ P.phosphoreum ${ }^{a}$} & \multicolumn{4}{|c|}{ V. harveyib } & \multicolumn{5}{|c|}{ V. fischeric } \\
\hline & & & & $\begin{array}{c}k_{\text {obs }} \\
\left(\mathrm{min}^{-1}\right)\end{array}$ & $\begin{array}{l}I_{\max } \\
\text { (rel) }\end{array}$ & $\begin{array}{c}K_{\mathrm{d}} \\
(\mu \mathrm{M})\end{array}$ & $\begin{array}{l}\lambda_{\max } \\
(\mathrm{nm})\end{array}$ & $\begin{array}{c}k_{\mathrm{obs}} f^{-1} \\
\left(\mathrm{~min}^{-1}\right)\end{array}$ & $\begin{array}{l}I_{\max } \\
\text { (rel) }\end{array}$ & $\begin{array}{c}K_{\mathrm{d}} \\
(\mu \mathrm{M})\end{array}$ & $\begin{array}{l}\lambda_{\max } \\
(\mathrm{nm})\end{array}$ & $\begin{array}{c}k_{\text {obs }} \\
\left(\min ^{-1}\right)\end{array}$ & $\begin{array}{l}I_{\max } \\
\text { (rel) }\end{array}$ & $K_{\mathrm{d}}(\mu \mathrm{M})$ & $\begin{array}{l}\lambda_{\max } \\
(\mathrm{nm})\end{array}$ & $\begin{array}{c}E_{\mathrm{a}^{\mathrm{g}}} \\
(\mathrm{kJ} / \mathrm{mol})\end{array}$ \\
\hline $\begin{array}{r}1 \\
2 \\
3 \\
4 \\
5 \\
6 \\
7 \\
8 \\
9 \\
10 \\
11 \\
12\end{array}$ & $\begin{array}{l}-\mathrm{NH}_{2} \\
\text {-OMe } \\
\text { - Me } \\
\text { - } \mathrm{H} \text { (nor) } \\
-\mathrm{Cl} \\
-\mathrm{F} \\
-\mathrm{SMe} \\
-\mathrm{SOMe}^{-} \mathrm{Me}^{-} \\
-\mathrm{SO}_{2} \mathrm{Me} \\
-\mathrm{iso}^{i} \\
-\mathrm{OEt} \\
-\mathrm{Br}\end{array}$ & $\begin{array}{l}-310 \\
-260 \\
-208 \\
-180 \\
-152 \\
-167 \\
-204 \\
-161 \\
-50 \\
-200 \\
-246 \\
-148\end{array}$ & $\begin{array}{l}-320 \\
-530 \\
-760 \\
-850 \\
-960 \\
-850 \\
-670 \\
-750 \\
-1220 \\
-780 \\
-550 \\
-950\end{array}$ & $\begin{array}{l}28 \\
13 \\
\\
6.6\end{array}$ & $\begin{array}{c}5.2 \\
100 \\
6.3\end{array}$ & $\begin{array}{l}3 \\
0.6 \\
0.45\end{array}$ & $\begin{array}{l}510 \\
480 \\
\\
465\end{array}$ & $\begin{array}{l}340 / 42 \\
51 / 16 \\
1.9 \\
4.4 / 0.8 \\
10.6 / 1.6 \\
7.5 \\
68 / 16 \\
5 / 0.3 \\
9\end{array}$ & $\begin{array}{c}120 \\
100 \\
11 \\
6.7 \\
8.0 \\
2.4 \\
0.2 \\
0.17 \\
4.7\end{array}$ & $\begin{array}{l}0.4 \\
0.3 \\
0.65 \\
0.09 \\
0.25 \\
2 \\
\text { nd }^{h} \\
\mathrm{nd}^{h} \\
0.7\end{array}$ & $\begin{array}{l}515 \\
490 \\
485 \\
473 \\
482 \\
495 \\
\text { nd }^{h} \\
\text { nd }^{h} \\
488\end{array}$ & $\begin{array}{l}0.46 \\
0.43 \\
0.39 \\
0.07 \\
0.19\end{array}$ & $\begin{array}{c}11.5 \\
100 \\
30 \\
7.2 \\
9.6\end{array}$ & $\begin{array}{c}28 \\
10 \\
13 \\
3.5 \\
15\end{array}$ & $\begin{array}{l}500 \\
489 \\
487 \\
480 \\
485\end{array}$ & $\begin{array}{l}\mathrm{nd}^{h} \\
53 \\
56 \\
106 \\
78\end{array}$ \\
\hline
\end{tabular}

a $T=20^{\circ} \mathrm{C}$; tridecanal; $I_{\max }$ in $\%$ of FMN (3); data from Watanabe et al. (1978). ${ }^{b} T=25^{\circ} \mathrm{C}$; decanal; $I_{\max }$ in $\%$ of FMN (3). ${ }^{c} T=4{ }^{\circ} \mathrm{C}$; decanal; $I_{\max }$ in $\%$ of $\mathrm{FMN}(3),{ }^{d}$ Standard two-electron redox potentials for the couple $\mathrm{Fl}_{0 x} \leftrightarrow 1,5$-Dihydro- $\mathrm{Fl}_{\mathrm{rod}} \mathrm{H}_{2}$. Redox potentials $E^{\circ}$, for the couple $\mathrm{Fl}_{0 \mathrm{x}}$ $\leftrightarrow \mathrm{Fl}_{\mathrm{red}} \mathrm{H}_{2}$, the values reported are those for the riboflavin derivatives. See Materials and Methods section for details. ${ }^{\bullet}$ One-electron potentials for the oxidation of 4a,5-dihydroflavin model compounds to the radical cation, calculated using appropriate Swain coefficients. The observed values for compounds 1-5, measured by cyclic voltametry, were $-275,-540,-720,-810$, and -925 , respectively, and are plotted in Figure $4 . f$ When two values (separated by /) are given, they refer to a fast and a slow rate, respectively, of light emission decay found in the same assay. See text for further details. 8 Arrhenius activation energies, determined by measurements of the rates at $4,12,20$, and $25^{\circ} \mathrm{C}$. ${ }^{h}$ Not determined; intensity of bioluminescence was too low for accurate measurements. ${ }^{i}$ Iso- $\mathrm{FMNH}_{2}=8$-nor-6,7-dimethyl-FMNH${ }_{2}$. 


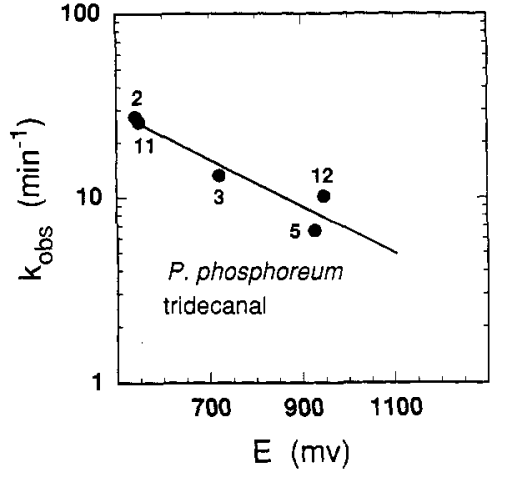

Figure 7: Plot as in Figure 5 for data (Table III) with $P$. phosphoreum and tridecanal at $20^{\circ} \mathrm{C}$ from Watanabe et al. (1978).

to be able to react with reduced FMN analogs carrying large substituents at position 8 (Chen \& Baldwin, 1984).

We have also plotted (Figure 7) the rates reported by Watanabe et al. (1978) for the reaction of $P$. phosphoreum luciferase with the analogs $2,11,3,5$, and 12 , with tridecanal as the aldehyde (Table III). The same trend toward faster decay of light intensity at lower flavin oxidation potentials is clearly apparent.

Judging from the data obtained with $V$. fischeri luciferase with decanal and tetradecanal, the chain length of the aldehyde does not appear to have a strong influence dependence of $k_{\mathrm{obs}}$ on $E$. It can also be noted that the initial intensity $\left(I_{\max }\right)$ does not appear to be a good parameter for comparisons with $E$. Additional studies concerned with these questions are warranted. Also, dissociation constants of the reduced FMN analogs do not correlate with the rates of light emission decay in the bioluminescence assay (Table III). Generally, halogenated derivatives of reduced flavin bind better (lower $K_{\mathrm{d}}$ ) than $\mathrm{FMNH}_{2}$ itself but exhibit slower rates of light emission decay. The behavior of 8-methoxy-FMNH ${ }_{2}$ (2) with $V$. harveyi luciferase is notable: in spite of its bulky nature, this analog produces a slightly higher light emission intensity as compared to $\mathrm{FMNH}_{2}$, while binding more weakly to luciferase.

\section{CONCLUSIONS}

From the data of Table III, we conclude that the effect of substituents at position 8 of the flavin molecule on the catalytic turnover cannot be explained simply by steric factors and that electronic effects are important. A trend indicative of a relationship between the rates of light intensity decay and the oxidation potentials of the enzyme-bound 4a,5-dihydroflavin moieties, as required by the CIEEL mechanism, was found with all luciferases investigated. This suggests that the electron-donating capacity of the 4a,5-dihydroflavin intermediate determines the rate of cleavage of the $\mathrm{O}-\mathrm{O}$ bond, which is weak (Merenyi \& Lind, 1992), and ultimately the production of the excited state.

An open issue in the interpretation of the data is whether the excitation process is due to charge annihilation, as postulated in the CIEEL mechanism, or whether partial charge transfer could cause $\mathrm{O}-\mathrm{O}$ bond cleavage and result directly in the population of excited states (Catalani \& Wilson, 1989; Wilson, 1985).

Hydroperoxide cleavage in the bacterial luciferase reaction appears to proceed by a unique mechanism, basically different from that of other flavin-dependent monooxygenases or hydroxylases (Ghisla \& Massey, 1989). In particular, in our view, the present data are not compatible with a mechanism of the Baeyer-Villiger type (Eberhard \& Hastings, 1972;
Ahrens et al., 1991). In that mechanism, which is operational in flavin-dependent monooxygenases such as cyclohexanone monooxygenase (Walsh \& Chen, 1988), the opposite dependence would be expected: the reaction rate would increase with the redox potential. This is in line with the work of Bruice and co-workers (Bruice, 1982a,b, 1984; Bruice et al., 1983), who made a comprehensive chemical study of the influence of the hydroperoxide substituent $\mathrm{R}(\mathrm{R}-\mathrm{OOH})$ on the reactivity toward electrophilic molecules. Their work shows that monooxygen transfer is directly related to the $\mathrm{p} K_{\mathrm{a}}$ of R-OH (formed from R-OOH), i.e., that the cleavage of the peroxide bond proceeds via inductive polarization. This is equivalent to a mechanism in which the transfer of oxygen to substrate is dependent upon the ability of a Fl-4a-Ointermediate (or product) to accommodate the negative charge resulting from peroxide $\mathrm{O}-\mathrm{O}$ bond cleavage.

In recent studies, Mager et al. (1990) and Kaaret and Bruice (1990) have explored the production of chemiluminescence from the reactions of electrochemically generated $4 \mathrm{a}-\mathrm{OH}$ 5-ethyllumiflavin model compounds. Although the results of these two groups differed, both support the feasibility of a one-electron redox process with the 4a,5-dihydroflavins.

\section{ACKNOWLEDGMENT}

We appreciate the helpful comments of Drs. Hajime Karatani and Thérèse Wilson. The expert assistance of Dipl.Chem. Sonja Kroner with the cyclic voltammetry experiments is highly appreciated.

\section{REFERENCES}

Ahrens, M., Macheroux, P., Eberhard, A., Ghisla, S., Branchaud, B., \& Hastings, J. W. (1991) Photochem. Photobiol. 54, 295299.

Baldwin, T. O., Holzman, T. F., Holzman, R. B., \& Riddle, V. W. (1986) Methods Enzymol. 133, 98-108.

Baumstark, A. L., Cline, T. W., \& Hastings, J. W. (1979) Arch. Biochem. Biophys. 193, 449-455.

Berezovskii, V. M., Tul'chinskaya, L. S., \& Polyakova, N. A. (1972) Russ. Chem. Rev. 41, 574-591.

Bolognesi, M., Ghisla, S., \& Incoccia, L. (1978) Acta Crystallogr. B34, 821-828.

Bradford, M. M. (1976) Anal. Biochem. 72, 249-254.

Bruice, T. C. (1982a) in Oxidases and Related Redox Systems (King, T. E., \& Morrison, M., Eds.) pp 423-446, Pergamon Press Ltd., Tokyo.

Bruice, T. C. (1982b) in Flavins and Flavoproteins (Massey, V., \& Williams, C. H., Eds.) pp 265-277, Elsevier, New York.

Bruice, T. C. (1984) in Flavins and Flavoproteins (Bray, R. C., Engel, P., \& Mayhew, S. G., Eds.) pp 45-55, Walter deGruyter, Berlin, New York.

Bruice, T., Noar, J. B., Ball, S. S., \& Venkataram, U. V. (1983) J. Am. Chem. Soc. 105, 2452-2464.

Catalani, L. H., \& Wilson, T. (1989) J. Am. Chem. Soc. 111, 2633-2639.

Chen, L., \& Baldwin, T. O. (1984) in Flavins and Flavoproteins (Bray, R. C., Engel, P. C., \& Mayhew, S. G., Eds.) pp 785788, Walter deGruyter, Berlin, New York.

Dewar, M. J. S., Zoebisch, E. G., Healy, E. F., \& Stewart, J. J. P. (1985) J. Am. Chem. Soc. 107, 3902-3909.

Draper, R. D., \& Ingraham, L. L. (1968) Arch. Biochem. Biophys. $125,802-808$.

Eberhard, A., \& Hastings, J. W. (1972) Biochem. Biophys. Res. Commun. 47, 348-353.

Eckstein, J. W., Cho, K. W., Ghisla, S., \& Hastings, J. W. (1988) J. Biolum. Chemilum. 2 (4), 201.

Foust, G. P., Burleigh, B. D., Mayhew, S. G., Williams, C. H., \& Massey, V. (1969) Anal. Biochem. 27, 530-535. 
Fritz, B. J., Kasai, S., \& Matsui, K. (1990) Photochem. Photobiol. $51,607-610$.

Ghisla, S., \& Mayhew, S. G. (1980) Methods Enzymol. 66, 241253.

Ghisla, S., \& Massey, V. (1989) Eur. J. Biochem. 181, 1-17.

Ghisla, S., Hartmann, U., Hemmerich, P., \& Müller, F. (1973) Liebigs. Ann. Chem. 1388-1415.

Ghisla, S., Massey, V., Lhoste, J. M., \& Mayhew, S. G. (1974) Biochemistry 13, 589-597.

Ghisla, S., Entsch, B., Massey, V., \& Husain, M. (1977) Eur. J. Biochem. 76, 139-148.

Haas, W., \& Hemmerich, P. (1979) Biochemical J. 181, 95105.

Hastings, J. W., \& Gibson, Q. H. (1963) J. Biol. Chem. 238, 2537-2554.

Hastings, J. W., Balny, C., LePeuch, Ch. \& Douzou, P. (1973) Proc. Natl. Acad. Sci. U.S.A. 70, 3468-3472.

Hastings, J. W., Baldwin, T. O., \& Nicoli, M. Z. (1978) Methods Enzymol. 57, 135-152.

Hastings, J. W., Potrikus, C. J., Gupta, S., Kurfürst, M., \& Makemson, J. C. (1985) Adv. Microb. Physiol. 26, 235-291.

Hemmerich, P., Prijs, B., \& Erlenmeyer, H. (1959) Helv. Chim. Acta 172, 1604-1611.

Hemmerich, P., Prijs, B., \& Erlenmeyer, H. (1960) Helv. Chim. Acta 48, 372-394.

Kaaret, T. W., \& Bruice, T. C. (1990) Photochem. Photobiol. $51,629-633$.

Kasai, S., Kubo, Y., Yamanaka, S., Hirota, T., Sato, H., Tsuzukida, Y., \& Matsui, K. (1978) J. Nutr. Sci. Vitaminol. 24, 339-350.

Kasai, S., Yamanaka, S., Wang, S.-C., \& Matsui, K. (1979) J. Nutr. Sci. Vitaminol. 25, 289-298.

Kasai, S., Fritz, B. J., \& Matsui, K. (1987) Bull. Chem. Soc. Jpn. 60, 3041-3042.

Keum, S. R., Gregory, D. H., \& Bruice, T. C. (1990) J. Am. Chem. Soc. 112, 2711-2715.

Kiesele, H. (1980) Anal. Chem. 52, 2230-2232.

Kiesele, H. (1981) Anal. Chem. 53, 1952-1954.

Koo, J. Y., \& Schuster, G. B. (1977) J. Am. Chem. Soc. 99, 6107-6109.

Light, D. R., \& Walsh, C. (1980) J. Biol. Chem. 255, 42644277.
Macheroux, P., Ghisla, S., Kurfürst, M., \& Hastings, J. W. (1984) in Flavins and Flavoproteins (Bray, R. C., Engel, P., \& Mayhew, S. G., Eds.) pp 669-672, Walter deGruyter, Berlin, New York.

Macheroux, P., Eckstein, J., \& Ghisla, S. (1987) in Flavins and Flavoproteins (Edmondson, D. E., \& McCormick, D. B., Eds.) pp 613-619, Walter deGruyter, Berlin, New York.

Macheroux, P., Kojiro, C. L., Schopfer, L. M., Chakraborty, S., \& Massey, V. (1990) Biochemistry 29, 2670-2679.

Mager, H. I. X., \& Addink, R. (1984) in Flavins and Flavoproteins (Bray, R. C., Engel, P. C., \& Mayhew, S. G., Eds.) pp 37-40, Walter deGruyter, New York.

Mager, H. I. X., Sazou, D., Liu, Y. H., Tu, S. C., \& Kadish, K. M. (1988) J. Am. Chem. Soc. 110, 3759-3762.

Makemson, J. C., Hastings, J. W., \& Quirke, M. W. (1992) Arch. Biochem. Biophys. 294, 361-366.

McCormick, D. B., Arsenis, C., \& Hemmerich, P. (1963) J. Biol. Chem. 238, 3095-3099.

Meighen, E. A., \& Hastings, J. W. (1971) J. Biol. Chem. 246, 7666-7674.

Merenyi, G., \& Lind, J. J. (1992) J. Am. Chem. Soc. 113, 31463153.

Mitchell, G., \& Hastings, J. W. (1969) J. Biol. Chem. 244, 25722576.

Moore, E. G., Ghisla, S., \& Massey, V. (1979) J. Biol. Chem. 254, 8173-8178.

Müller, F., \& Massey, V. (1969) J. Biol. Chem. 244, 4007-4016.

Ruby, E. G., \& Hastings, J. W. (1980) Biochemistry 19, 49894993.

Schuster, G. B. (1979) Acc. Chem. Res. 12, 366-373.

Stewart, R. C., \& Massey, V. (1985) J. Biol. Chem. 260, 1363913647.

Swain, C. G., \& Lupton, E. C., Jr. (1968) J. Am. Chem. Soc. $90,4328-4337$.

Swain, C. G., Unger, S. H., Rosenquist, N. R., \& Swain, M. S. (1983) J. Am. Chem. Soc. 105, 492-502.

Tu, S. C. (1979) Biochemistry 18, 5940-5945.

Walsh, C. T., \& Chen, Y. C. J. (1988) Angew. Chem. 100, 342352.

Watanabe, T., Matsui, K., Kasai, S., \& Nakamura, T. (1978) J. Biochem. 84, 1441-1446.

Wilson, T. (1985) in Singlet Oxygen (Frimer, A. A., Ed.) Vol. 2, pp 37-65, CRC Press, Boca Raton, FL. 